\title{
Perspektif Pembinaan Tim Puslatda Wushu Sanshou Jawa Timur Dalam Persiapan Pekan Olahraga Nasional (PON) Yang Ke-Xix Tahun 2016 Di Jawa Barat
}

\author{
Efi Dian Sofiana, Tutur Jatmiko
}

Universitas Negeri Surabaya, Kampus Unesa Lidah Wetan, Surabaya 60213, Indonesia

*Corresponding author: efisofiana@mhs.unesa.ac.id

\section{ARTICLE INFO}

\section{Article history:}

Received : 02 Juni 2017

Received in revised form: 10

Oktober 2017

Accepted: 20 Februari 2018

Keywords: Management, Wushu Sanshou, National Sport Week.

\begin{abstract}
Wushu Sanshou is a martial sport of China and background research is to determine the development of athlete puslatda Wushu Sanshou East Java. National sport week is a national sport festival held every 4 years that followed by province exist in Indonesia. Almost all kind of sports are contested in this festival including Wushu Sanshou. The purpose of this study is to find perspective management team puslatda Wushu Sanshou East Java in preparation national sports that XIX years 2016 in West Java. to improve their performance athletes of course affected many factors among them: the athletes, coach, organization facilities, nature about, participation government.

The research is qualitative study by using the method descriptive. The collection locations data was undertaken in school the national academy Surabaya star who is also a place of exercise training for athletes puslatda Wushu Sanshou East Java. The subject of study was chairman of the wushu, coach, and athletes puslatda Wushu Sanshou East Java.

The results of data processing conducted using data analysis through interviews with the subject of study was chairman of, coach, athletes puslatda Wushu Sanshou East Java. The conclusion of the research is guidance on a KONI East Java good, complete infrastructure facilities, an exercise program that has been programmed in a systematic and planned from 2013 until 2016. In addition there is also a supporting factor inhibiting factor is the lack of good steward ship less compact in which the team of administrators athletes and coaches becomes harmonious relationship
\end{abstract}

\section{Pendahuluan}

Olahraga adalah sebuah aktivitas manusia yang bertujuan untuk mencapai kesejahteraan jasmani dan rohani manusia itu sendiri. Olahraga dimasa sekarang ini sudah merupakan salah satu aktifitas yang penting dalam kehidupan manusia. Tujuan orang melakukan aktivitas olahraga bermacam-macam tergantung pada kondisi, situasi, kebutuhan, dari masingmasing individu misalnya untuk mencapai prestasi, untuk menjaga kesehatan, untuk penyembuhan. Pembinaan dan pembibitan olahraga merupakan permasalahan penting yang harus mendapat perhatian. Upaya peningkatan prestasi olahraga perlu terus dilaksanakan melalui pencarian dan pemanduan bakat, pembibitan, pendidikan dan pelatihan olahraga prestasi yang didasarkan pada ilmu pengetahuan dan teknologi secara lebih efektif dan efisien serta peningkatan kualitas olahraga baik tingkat pusat maupun daerah.

Secara resmi, olahraga wushu yang bernaung dalam Federasi Wushu Internasional (IWUF) mempertandingkan tiga nomor, yaitu : Taolu (Peragaan bentuk jurus), Tuida (Peragaan 
pertarungan), Sanshou/Sanda (Pertarungan bebas). Pada pertandingan wushu selain mempertandingkan teknik memainkan senjata juga ada kategori pertarungan Sanshou. Shansou sekilas mirip kickboxing atau thaiboxing, apalagi sama-sama mengenakan celana pendek bersarung tinju. Perbedaannya petarung Sanshou memakai kaos dan kepala dilindungi pengaman. Prestasi Wushu Jawa Timur adalah mampu meraih peringkat ketiga pada Kejuaraan Nasional (Kejurnas) Wushu di Medan tahun 2014 dengan meraih lima medali emas, dua perak dan satu perunggu. Untuk Wushu Sanshou sendiri mendapat juara umum, mereka mendapat tiga emas. Melihat prestasi Tim Wushu Jawa Timur dapat dikatakan bagus karena ditinjau dari prestasi yang dicapai. Meski ada kendala dalam peralatan tanding, atlet wushu Jatim mampu meraih hasil lumayan dalam ajang Pra PON di Jawa Barat pada tanggal 22-26 September 2015 kemarin. Wushu Jawa Timur mampu merebut lima medali emas, dan merebut posisi ketiga.

Berdasarkan latar belakang masalah yang diuraikan maka peneliti mempunyai pemikiran untuk mengadakan penelitian tentang "Perspektif Pembinaan Tim Puslatda Wushu Sanshou Jawa Timur Dalam Persiapan Pekan Olahraga Nasional (PON) Yang ke-XIX Tahun 2016 di Jawa Barat". Yang diharapkan dapat mengetahui pembinaan Tim Puslatda Wushu Shansou Jawa Timur ini sejauh mana sehingga dapat mencapai target dan sukses di Pekan Olahraga Nasional tahun 2016 di Jawa Barat.

\section{Metode Penelitian}

Metode penelitian yang digunakan adalah penelitian kualitatif menggunakan metode deskriptif dan teknik pengumpulan datanya menggunakan interview (wawancara) bebas terpimpin. Dengan demikian pewawancara bebas menanyakan apa saja dengan membawa sederetan pertanyaan lengkap dan terperinci metode untuk wawancara dengan Ketua Harian, Pelatih dan Atlet Puslatda Wushu Sanshou Jawa Timur. Secara spesifik dapat dikemukakan bahawa peneliti ingin mengungkapkan dan meneliti Perspektif Pembinaan Tim Puslatda Wushu Sanshou Jatim dalam persiapan Pekan Olahraga Nasional (PON) yang Ke-XIX Tahun 2016 di Jawa Barat.
3. Hasil

Sesuai dengan fokus penelitian, tujuan penelitian dan hasil penelitian tentang Perspektif Pembinaan Tim Puslatda Wushu Sanshou Jawa Timur Dalam Persiapan Pekan Olahraga Nasional (PON) Yang Ke-XIX Tahun 2016 di Jawa Barat, diketahui bahwa:

\section{a. Sistem penyelenggaraan dan pendanaan Tim Puslatsa Wushu Jatim}

Sistem penyelenggaraan wushu Sanshou Jawa Timur berawal dari kerjasama KONI JATIM dengan pelatih, atlet dan pengurus. pengolahan dana dari KONI JATIM juga bersifat terbuka sehingga proses kegiatan latihan di Tim Puslatda Wushu Sanshou Jawa Timur berjalan dengan lancar sesuai dengan rencana program kerja dan pembinaan yang ditetapkan sebelumnya. Semua anggaran baik anggaran untuk pengajuan semua perlengkapan sarana dan prasarana latihan dan tanding, dana untuk try-out keluar negeri langsung dianggarkan dan diolah oleh pelatih puslatada Wushu Jawa Timur langsung.

\section{b. Pelaksanaan Pembinaan atlet Puslatda Wushu Sanshou}

Pelaksanaan program pembinaan di tim Puslatda Wushu Sanshou dapat dikatakan sudah berjalan dengan baik karena pada prosesnya tidak banyak mengalami hambatan atau kendala yang berarti. Tim puslatda jatim ini adalah badan yang dibentuk oleh KONI Jatim untuk mengatur seluruh kegiatan puslatda yang di ketuai oleh seorang Direktur Puslatda, organisasi yang terdiri dari tiga pilar yakni : kesehatan, fisik, dan psikologi. Sistem pembinaan di puslatda ini menggunakan sistem tiga pilar yang tersebut diatas, secara berkelanjutan dan pengawasan oleh masing pilar ke tiap-tiap cabang olahraga kemudian target medali dijadikan sebagai tolak ukur atlet dalam melaksanakan puslatda sehingga ada reward dan punishment.

Program latihan selama kurun waktu tiga tahun sampai pelaksanaan Pekan Olahraga Nasional adalah waktu yang lama, sehingga program latihan harus berjangka panjang dan berkelanjutan dan tidak boleh putus. Program latihan, diantaranya latihan fisik, latihan teknik, latihan taktik dan mental. Harus ada target latihan dan kompetisi pada puncaknya pelaksanaan PON tersebut. Disiplin, 
kekompakan harus ditanamkan di dalam tim, semangat, pantang menyerah dan berdoa, musuh terbesar yaitu rasa malas. Latihan fisik diberikan setiap pagi yaitu hari senin, rabu, jumat dan sabtu. Untuk hari selasa dan rabu pagi jadwal mereka latihan beban / fitness. Sore hari melaksanakan latihan di dalam matras. Dari hasil pengamatan saya pada Tim Puslatda Wushu Sanshou ini, mereka berlatih 10x dalam seminggu dan $2 x$ sehari tergantung jarak kurun waktu dengan pertandingan, jika saat pertandingan sudah masuk pada persiapan khusus dan pra kompetisi mereka melakukan latihan satu hari bisa 3x. Latihan dilakukan setiap hari dimulai dari hari senin-sabtu, latihan pagi senin, rabu, jumat dan sabtu meraka melakukan latihan drill fisik dilapangan KONI Jatim. Latihan beban dijadwalkan hari selasa dan kamis pagi dan setiap sore hari mereka latihan di matras di gedung Sekolah Nation star academy. Mereka libur latihan hari Kamis, Sabtu sore dan Minggu, jadwal latihan pagi mereka start dari jam $06.00 \mathrm{~s} / \mathrm{d} 08.00$ dan sore jam $16.00 \mathrm{~s} / \mathrm{d}$ 17.30. Program latihan persiapan umum dan khusus yang diterapkan oleh tim Puslatda Wushu Sanshou ini dirasakan para atlet sudah sesuai dengan kebutuhan dan kondisi atlet, dimana para atlet tidak ada tekanan selama mengikuti program latihan yang diterapkan.

Pada persiapan pra kompetisi atlet puslatda wushu sanshou Jawa Timur try-out di Cina bisa disimpulkan bahwa program latihan di Cina tidak berjalan dengan baik dan terkendala dengan bahasa.

Untuk mencapai suatu prestasi harus ada pendukungnya, salah satunya adalah fasilitas yang memadai di tim Puslatda Wushu Sanshou ini telah menyediakan berbagai perlengkapan untuk atletnya guna menunjang latihan. Fasilitas yang diberikan adalah berupa :
a. Lapangan
b. Matras
c. Peralatan tanding
d. Asrama untuk atlet
e. Pemberian bonus dari KONI
f. Program latihan dan tim kepelatihan
g. Asupan vitamin / gizi

Hal ini menunjukan bahwa dalam pencapaian prestasi di olahraga sangat dipengaruhi oleh sarana dan prasarana yang memadai untuk pencapaian prestasi di olahraga itu sendiri. Dalam hasil pengamatan saya mengenai gizi para atlet, saya telah melakukan wawancara dengan pengurus, pelatih, dan atlet dalam hal gizi atlet. Untuk gizi mereka sama KONI benar-benar diperhatikan betul. Mereka dapat pemberian jatah dari tim gizi KONI Jatim berupa suplemen makanan, glucosamine dan susu. Setiap bulannya mereka selalu melakukan tes bia, supaya tahu ada perkembangan progress setiap bulannya. Bagi yang suplemen dapat dari KONI atlet membelinya dengan biaya uang pribadi sendiri. Atlet yang menurunkan berat badan mendapat pantauan khusus untuk mengontrol berat badannya

Sarana dan prasarana yang ada di tempat latihan puslatda wushu sanshou sudah baik dan bagus. Segala peralatan latihan atau kebutuhan berlatih sudah terpenuhi. Begitupun dengan peralatan bertanding mereka juga mendapatkan jatah juga. Hanya untuk puslatda Wushu Sanshou ini mereka belum punya gedung tempat latihan sendiri, tetapi KONI memberikan sebuah dana untuk atlet puslatda wushu ini menyewa tempat untuk latihan. Sarana dan prasarana merupakan faktor penting yang mempengaruhi kualitas latihan untuk mencapai prestasi, karena dengan adanya sarana prasarana yang lengkap maka akan memperlancar pencapaian prestasi. Partisipasi yaitu hampir semua difasilitasi oleh pemerintah lewat APBD Jatim, anggaran dari KONI itu seluruhnya dari provinsi Jatim dan tidak ada dana dari yang lain. Untuk meraih hasil yang maksimal, dinas dan Kepemudaan dan Keolahragaan (DISPORA) Jatim, mengumpulkan SKPD dan cabang olahraga. Pemerintah Jatim atas nama Gubernur menugaskan SKDP untuk ikut memberikan motivasi dan monitoring atlet Cabor Puslatda Jatim. Dana ini dari provinsi lewat biro kesejahteraan masyarakat (BIROKESMAS). Dan partisipasi pemerintah semuanya berupa uang dan materi, Cabang Olahraga wushu kemarin mendapat dukungan SKPD yang diperintah langsung oleh Gubernur Jatim dari DISNAKER. 


\section{c. Faktor yang memperngaruhi prestasi atlet wushu}

Faktor yang mempengaruhi pembinaan Tim Puslatda Wushu Sanshou ini ada dua yakni faktor pendukung dan penghambat. Faktor inilah yang selama ini mempengaruhi keberhasilan atlet puslatda Wushu Sanshou Jatim. Faktor pendukung dalam pembinaan puslatda Wushu Sanshou tersebut antara lain memiliki pengalaman dan daya juang yang bagus, kemampuan daya saing yang cukup tinggi, berlatih keras dan bersungguh-sungguh. Pelatih lokal yang melatih pada tim Puslatda Wushu Sanshou ini dapat dibilang pelatih profesional karena selain sangat menguasai dalam teknik olahraganya, beliau juga memiliki pengalaman yang sudah tidak diragukan lagi. Salah satu dari Beliau pernah mengharumkan nama bangsa kita pada Sea-Games 2011. Dan gizi atlet puslatda wushu Sanshou ini sudah bagus dan baik selayaknya cabang olahraga lainya. Sarana dan prasarana atlet Puslatda Wushu Sanshou Jatim ini baik dan sesuai dengan standart. Atlet juga mendapatkan uang saku setiap bulannya sebagai biaya hidup selama mengikuti latihan dan menjadi anggota Tim Puslatda Wushu Sanshou Jatim. Bonus adalah sumber energi bagi atlet untuk bisa memotivasi dirinya. Dan atlet yang ikut PON mendapat penghargaan bonus sesuai dengan hasil yang dicapai. Atlet puslatda Wushu Sanshou mendapat dana dari KONI JATIM untuk melakukan try- out di China. Mendapat partisipasi dari pemerintah berupa morill maupun materill yang mendapat dukungan SKPD yang berkerjasama dengan DISNAKER.

Dengan adanya faktor pendukung pasti ada juga faktor penghambat bagi Tim Puslatda Wushu Sanshou antara lain mengenai kurangnya kepengurusan yang baik antara pelatih dengan pengprov atau pengurus, kurang kompak pada tim dimana antara pengurus atlet dan pelatih sehingga terjadi kesala pahaman, terkendala bahasa dengan pelatih asing, kejenuhan pada atlet saat latihan dan atlet yang sering bertanding itu semakin lama bisa menunjukan dirinya sendiri kelemahannya ada dimana, jadi lawan-lawan bisa membaca kekuatannya ada dimana, kurangnya personil sparing patner yaitu lawan yang dianggap lebih berat sehingga para atlet dapat lebih berkembang bukan jalan ditempat dan maka dari itu dibutuhkan pengalaman bertanding dan jam terbang yang tinggi untuk memenangkan pertandingan itu. Kecurangan wasit saat pertandingan kemarin, perlu pembangunan gedung latihan sendiri agar tidak menyewa terus-menerus, dan sponsor dana. Keinginan menjadi atlet ini harus di dukung pula oleh kemampuan individu tiap atlet yang memang rata-rata untuk naik ke level senior banyak persaingannya. Maka dari itu dibutuhkan pengalaman bertanding dan jam terbang yang tinggi untuk memenangkan persaingan itu.

\section{d. Prestasi apa saja yang diperoleh oleh atlet puslatda Wushu Sanshou jatim}

Prestasi adalah satu kegiatan olahraga dilakukan serta di kelola dengan yang professional.cara pengelolaan yang professional inilah yang memiliki tujuan guna mendapatkan atau meraih satu bentuk prestasi tertentu didalam jenis olahraga yang di lakukan.prestasi olahraga dijalankan dengan persiapan yang matang dan terprogram. Didalamnya juga diperlukan adanya proses yang baik untuk kemudian membentuk satu olahraga yang didalam mmencetak atau meraih prestasi yang ditentukan. Jadi baik dan tidaknya sebuah program pembinaan dapat dilihat dari hasil raihan prestasi yang telah didapat. Beberapa prestasi yang berhasil diraih oleh atlet Puslatda Wushu Sanshou dapat dikatakan cukup baik. Hal ini didasarkan dari hasil raihan prestasi yang diperoleh beberapa atlet.

Berikut ini adalah raihan prestasi yang didapat oleh atlet Puslatda Wushu Sanshou :

1. Yoseph. F. Neonub :

a) Pekan Olahraga Nasional Kaltim tahun 2008 juara 3 ,

b) Kejurnas tahun 2009 dan 2010 juara 1 ,

c) Pra-PON 2011 juara 1,

d) Pekan Olahraga Nasonal Riau tahun 2012 juara 3,

e) Kejurnas 2014 juara 1 ,

f) Pra-PON tahun 2015 juara 1,

g) Kejuaraan dunia tahun 2015 juara 1

h) Perak PON 2016

2. Gunawan :

a) Emas kejurnas 2014,

b) Emas Pra-PON 2015,

c) Perunggu kejuaraan dunia 2015 
d) Perunggu PON 2016

3. Kubarul .F. Oscar Yakut :
a) Emas Kejurnas junior tahun 2007,
b) Juara 1 seleknas tahun 2008 ,
c) Juara 3 Kejuaraan dunia 2008,
d) Emas Kejurnas 2009,
e) Juara 1 Seleknas tahun 2009,
f) Emas Kejurnas tahun 2010,
g) Emas Kejurnas 2014,
h) Perunggu Kejurnas Pra-PON tahun 2015
i) Perak PON 2016

\section{Sujada Sumiati}
a) Juara 1 Porprov 2015
b) 8 besar Pra-PON 2015
c) Perunggu PON 2016

Dari nama-nama atlet diatas mereka telah mengharumkan nama bangsa dan rakyat Jawa Timur terutama dibidang cabang olahraga Wuhsu Sanshou, atlet-atlet tersebut dibina Tim puslatda Jawa Timur. Suatu badan yang dibentuk oleh KONI Jatim untuk mengatur seluruh kegiatan puslatda yang di ketuai oleh seorang Direktur puslatda, organisasi yang terdiri dari tiga pilar yakni : kesehatan, fisik, dan psikologi oleh KONI JATIM sehingga mereka berhasil mencetak rekor dan prestasi diberbagai event-event Nasional maupun Internasional. Untuk hasil PON 2016 kemarin atlet puslatda wushu sanshou jatim mengalami kegagalan, karena pada Pekan Olahraga Nasional Jawa Timur kemarin tidak bisa membawah pulang medali emas. Dan Wushu Sanshou Jatim pada PON di Jawa Barat ditarget oleh KONI JATIM 2 medali emas. Hasil PON 2016 kemarin wushu dari sanshou Jawa Timur adalah 2 perak dan 2 perunggu. Artinya dalam hal ini wushu sanshou jatim bisa dikatakan gagal tidak memenuhi target yang sudah ditargetkan dari awal oleh KONI Jawa Timur. Kegagalan kemarin harus bisa dijadikan cambuk oleh cabang olahraga wushu sanshou khususnya untuk kedepannya, agar Pekan Olahraga Nasional yang ke XX di PAPUA pada tahun 2020 bisa menjadi lebih baik lagi.

\section{Simpulan Dan Rekomendasi}

Beberapa kesimpulan yang bisa diperoleh dari sistem pembinaan Wushu ini adalah :

a. Sistem pembinaan yang ada di tim puslatda wushu sanshou jatim dapat dikatakan sudah baik, yaitu melalui organisasi KONI JATIM dan menggunakan sistem 3 pilar (fisik, gizi, dan psiko) . Standar pelatih yang berkualitas dan sudah memiliki lisensi kepelatihan

b. Sarana prasarana yang dimiliki oleh tim Puslatda Wushu Sanshou ini sudah bagus dan memadai yaitu : lapangan, tem,pat fitnes, perlengkapan latihan dan pertandingan

c. Program latihan yang sudah terprogram secara sistematis dan terencana dari 2013 -2016. Program latihan dari persiapan umum dan khusus sudah bagus, tapi untuk program prakompetisi tidak berjalan dengan bagus, harus dievaluasi dan ditingkatkan lagi.

d. Faktor pendukung prestasi atlet puslatda wushu sanshou adalah : atletnya memiliki daya juang dan daya saing yang bagus, gizi atlet yang terpenuhi, sarana-prasarana latihan lengkap, atlet try out di Cina, dan yang mendapat juara di PON 2016 mendapat bonus seusai dengan hasil medali yang didapat. Sedangkan faktor penghambat yaitu : kurangnya kepengurusan yang baik, kurang kompak pada tim dimana antara pengurus atlet dan pelatih sehingga terjadi kesalahpahaman, terkendala bahasa dengan pelatih asing, kejenuhan pada atlet saat latihan, kurangnya personil sparing patner, program latihan yang tidak lancar saat di Cina, kecurangan wasit saat pertandingan, perlu pembangunan gedung latihan sendiri, dan sPONsor dana.

e. Partisipasi pemerintah untuk cabang olahraga wushu adalah mendapat partisipasi berupa morill dan materiil dan didukung langsung oleh SKPD yang berkerjasama dengan DISNAKER.

f. Hasil PON 2016 yang ke XIX Jawa Barat gagal, mendapat 2 perak dan 2 perunggu.

Sesuai kesimpulan yang didapatkan dan apa yang penulis temukan dalam penelitian ini, maka penulis sampaikan saran sebagai berikut : 
a. Meningkatkan kualitas latihan dengan penuh disiplin, agar dalam program latihan dapat terlaksana dengan baik.

b. Program latihan harus ditingkatkan lagi, agar performance bisa lebih bagus lagi.

c. Menambah atlet sparing dan harus sering untuk melakukan latih tanding ( sparingan ) agar pengalaman atlet bertambah matang dan banyak.

d. Menambah sPONsor dana.

e. Pengurus sendiri perlu juga memberikan bonus kepada atlet apabila atlet tersebut telah meraih prestasi. Karena dengan adanya apresiasi tersebut dapat menambah motivasi tersendiri bagi atlet.

f. Penambahan jumlah pelatih, untuk membantu jalannya program pelatih dengan lancar.

g. Hubungan pengurus, pelatih dan atlet ditingkatkan lagi agar dalam tim hubungannya tetap terjalin harmonis.

\section{UCAPAN TERIMA KASIH}

Kami ucapkan terima kasih kepada Tim Puslatda Wushu Sanshou Jawa Timur yang telah memberi kami izin untuk melakukan penelitian terhadap atlet-atlet wushu.

\section{DAFTAR PUSTAKA}

Arikunto, S.2006. Prosedur penelitian (Edisi revisi). Jakarta: PT Rineka Cipta.

Badudu, 2001. Kamus Umum Bahasa Indonesia. jakarta : Pustaka Sinar Harapan.

Gunawan, Gugun, 2007. Teks dan ilustrasi Bela Diri.Yogyakarta:Insan Madani.

Gunarsa,2004. Psikologi Olahraga Prestasi.Jakarta: PT Bpk Gunung Mulia

Badudu, Zein 1994. Kamus Umum Bahasa Indonesia.Jakarta: Pusat Sinar Harapan.

Bompa, Tudor O, 2009 Periodization Theory And Methodology of Training, 5th edition, Dubuque. Lowa.

Hadisasmita, Y. 1996.Ilmu Kepelatihan Dasar.Jakarta: Departeman Pendidikan dan kebudayaan Direktorat Jederal Pendidikan Tinggi.

Harsono, 1988. Coaching Aspek-Aspek Psikologi Dalam coaching. Jakarta: Departemen Pendidikan dan Kebudayaan Direktorat jenderal.

Lutan, Rusli. 2000. Manajemen penjaskes, Surabaya: Departemen Pendidikan dan Kebudayaan

Moleong, L.2009.Metodologi Penelitian kualitatif (Edisi revisi).Bandung: PT RemajaRosda karya Bandung.

Moleong, J Lexy, 2010, Metode Penelitian Kualitatif (Edisi revisi). Bandung: PT. Remaja Rosdakarya.

Saebani, Beni Ahmad 2008, Metode Penelitian.Bandung: CV. Pustaka Setia

Tim Penyusun. 2014. Panduan Penulisan dan Penilaian Skripsi Universitas Negeri Surabaya. Unesa University Press: Surabaya

Andriyanah Renny. 2014. Pembinaan Bolavoli Pantai Pengkab Di Kab.Sidoarjo. Surabaya: Unesa 